\title{
9. O Enigma da Respiração: Como Foi Decifrado
}

\author{
Joffre Marcondes de Rezende
}

\section{SciELO Books / SciELO Livros / SciELO Libros}

REZENDE, J. M. O Enigma da Respiração: Como Foi Decifrado. In: À sombra do plátano: crônicas de história da medicina [online]. São Paulo: Editora Unifesp, 2009, pp. 97-102. História da Medicina series, vol. 2. ISBN 978-85-61673-63-5. https://doi.org/10.7476/9788561673635.0010.

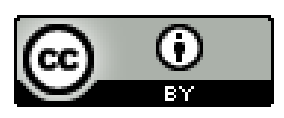

All the contents of this work, except where otherwise noted, is licensed under a Creative Commons Attribution 4.0 International license.

Todo o conteúdo deste trabalho, exceto quando houver ressalva, é publicado sob a licença Creative Commons Atribição 4.0.

Todo el contenido de esta obra, excepto donde se indique lo contrario, está bajo licencia de la licencia Creative Commons Reconocimento 4.0. 


\title{
O Enigma da Respiração: Como Foi Decifrado
}

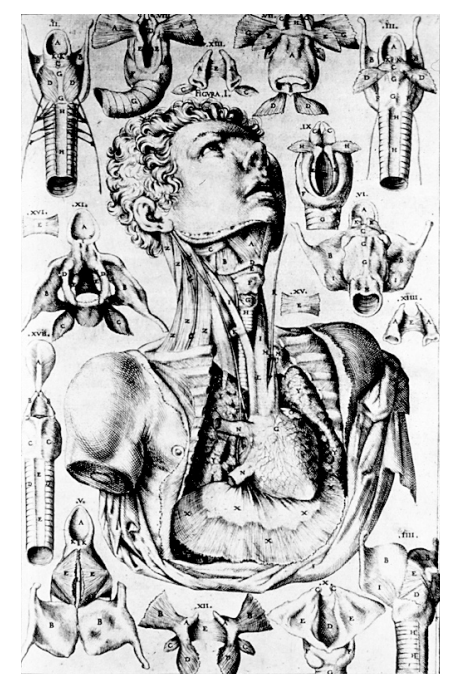

Anatomia do sistema respiratório, por Giulio Casserio (I552-I6I6).

\begin{abstract}
A s descobertas sobre a fisiologia da respiração são um exemplo típico de como evoluiu o conhecimento científico, por etapas, graças à contribuição de sucessivos pesquisadores - e de como continuará evoluindo, até que se torne possível decifrar o enigma com que a natureza desafia a inteligência humana.

A medicina egípcia via na respiração a função vital mais importante do organismo e o ar era considerado indispensável à preservação da vida. Segundo um texto no papiro de Ebers, o ar penetra pelas narinas, alcança o pulmão e o coração, de onde é distribuído a todo o corpo pelos vasos saguíneos (Leca, I97I, p. I 56). No mesmo papiro, em outra passagem, há referência ao sopro da vida e ao sopro da morte (Lopes, I969, p. 5I).

$\mathrm{Na}$ medicina hebraica a importância da respiração para a manutenção da vida é ressaltada no Livro dos Salmos (I04.29): "Se lhes tira a respiração, morrem, e voltam para o seu pó” (A Bíblia Sagrada, I981, p. 592).

Entre os filósofos gregos, Anaximenes (570-500 a.C.) considerava o ar o principal elemento da criação e sustentáculo da vida animal. Para a esco-
\end{abstract}


la hipocrática, o calor corporal é inerente à vida e para a conservação do calor é necessária a respiração, que introduz no corpo o pneuma, elemento vital contido no ar. A respiração leva o pneuma até os pulmões e, destes, ao ventrículo esquerdo, de onde é transportado pelas artérias a todas as partes do organismo (Entralgo, I970, pp. I69-170).

Na Idade Média, Leonardo da Vinci registrou, em um de seus cadernos de nota, que a chama de uma vela se apaga na ausência do ar (Fahraeus, I956, p. 579).

Robert Boyle (I627-I69I), físico inglês, confirmou a observação de Da Vinci, extraindo o ar de dentro de uma redoma de vidro por meio de uma bomba de aspiração. Verificou que a vida era impossível na atmosfera rarefeita dentro da redoma e que um pequeno animal ali colocado morria rapidamente. Portanto, alguma coisa havia no ar que alimentava ao mesmo tempo o fogo e a vida (Major, I954, pp. 5I4-5I5).

John Mayow (I643-I 679) repetiu as experiências de Boyle e constatou que quando se coloca ao mesmo tempo, dentro da redoma, um camundongo e uma vela, reduz-se pela metade o tempo necessário para apagar a chama e para a morte do animal. Ficou evidente que a porção de ar que alimentava a chama era a mesma que mantinha a vida. Tentou, a seguir, queimar um fragmento de cânfora no interior da redoma, após a extração do ar, fazendo convergir sobre o mesmo os raios solares concentrados por meio de uma lente. A combustão da cânfora só se processava quando se adicionava à mesma uma pequena quantidade de salitre (nitrato de potássio), substância empregada na fabricação da pólvora. Mayow concluiu que o nitrato contém a mesma substância existente no ar, necessária ao fogo e à vida. Chamou a esta substância spiritus nitroaereus. Em suas primeiras publicações, aos 25 anos de idade, Mayow combateu a teoria vigente desde o tempo de Galeno, de que o ar inspirado destinava-se a refrigerar o coração, e afirmou que a cor vermelha do sangue arterial se devia ao seu maior conteúdo em "ar do fogo" e que este era necessário para manter o calor do corpo. Mayow faleceu aos 36 anos de idade e seus trabalhos foram ignorados por quase um século (Fahraeus, op. cit., pp. 580-582).

Georg Stahl (I660-I734), no início do século XVIII, lançou a teoria flogística, segundo a qual todas as substâncias que se queimam têm na sua constituição um elemento comum, o flogisto, verdadeiro fogo latente, que se 
desprende durante a combustão. Esta teoria teve grande influência no pensamento médico, na interpretação da febre e da inflamação, que seriam causadas pela liberação dessa hipotética substância (Major, op. cit., p. 566).

Inflamar provém do latim inflammare, que significa "pôr em chamas". Data dessa época a denominação de antiflogístico, usada até hoje para designar as substâncias ou medicamentos dotados de ação anti-inflamatória.

Joseph Black (I728-I799), professor de Química em Glasgow, na Escócia, descobriu em 1757 que havia no ar atmosférico um gás com a propriedade de turvar a água de cal. Chamou a esse gás de "ar fixo" e identificou-o ao "gás silvestre" descoberto por Van Helmont um século antes. Verificou que o ar expelido pelos pulmões era mais rico deste gás do que o ar atmosférico, e que o mesmo também se formava com a queima do carvão (Idem, p. 6I3).

Em I766, Cavendish isolou o hidrogênio. William Henry Cavendish (I73 I-I 8 IO) era físico e químico inglês, descendente de família nobre e muito rica. Dedicou toda a sua vida à pesquisa científica e foi um dos pioneiros no estudo dos gases atmosféricos. Era um misantropo que evitava contato com as pessoas, inclusive parentes. Nunca se casou e sua convivência se limitava aos membros da Royal Society, a que pertencia, e onde comunicava as suas descobertas. Dentre elas, uma das mais importantes foi a identificação do hidrogênio, a que chamou de "ar inflamável". Por meio de uma centelha elétrica obteve a síntese da água, combinando o "ar inflamável” com o "ar do fogo", ou seja, o hidrogênio com o oxigênio, que ele chamava de "ar vital". Muitas de suas descobertas permaneceram desconhecidas de seus contemporâneos e só foram divulgadas muitos anos após sua morte (Idem, pp. 6I3-6I4).

O nitrogênio foi identificado independentemente por Scheele, Priestley e Rutherford em I772.

A esta altura, portanto, já haviam sido isolados o gás carbônico, o hidrogênio e o nitrogênio. Faltava ser identificado o oxigênio, até então chamado "ar do fogo" ou "ar vital". O oxigênio foi finalmente isolado, ao mesmo tempo, por Scheele e Priestley.

Carl Wilhelm Scheele (I742-I786), de nacionalidade sueca, era farmacêutico e fazia suas experiências em um pequeno laboratório nos fundos da farmácia onde trabalhava, na cidade de Upsala. Obteve o "ar do fogo" a partir do óxido de magnésio e, a seguir, do óxido de mercúrio. Observou 
que os animais colocados no recipiente onde era coletado o "ar do fogo", lentamente o transformavam em "ar fixo" (gás carbônico). Scheele deixou-se influenciar pela teoria flogística que dominava o pensamento científico na época e acreditava que a produção do calor se devia à liberação do flogisto, que se unia ao "ar do fogo". Scheele faleceu aos 43 anos de idade, dois dias após o seu casamento com a viúva do antigo dono da farmácia, convencido do acerto da teoria flogística (Fahraeus, op. cit., pp. 580-582).

Joseph Priestley ( I733-I 804), em Birmingham, na Inglaterra, também isolou em I772 o "ar do fogo", aquecendo diversas substâncias químicas. Notou que a chama era mais brilhante com o "ar do fogo" puro do que com o ar atmosférico. Explicou a combustão, do mesmo modo que Scheele, como resultado da liberação do flogisto contido nos corpos e sua união ao "ar do fogo". A queima de uma substância nada mais era, segundo Priestley, do que a retirada pelo gás, do flogisto, que se libertava (flogisto livre).

A respiração para ele tinha por fim levar o "ar do fogo" ao interior do organismo a fim de retirar do sangue o flogisto liberado pelos alimentos. A cor escura do sangue venoso seria devida ao maior teor de flogisto e a cor vermelha do sangue arterial ao processo de desflogistificação, isto é, à retirada do flogisto pelo ar dos pulmões.

Priestley era um sacerdote e teve de fugir da Inglaterra para os Estados Unidos por suas convições religiosas. Enquanto viveu manteve sua crença na teoria flogística (Major, op. cit., pp. 6I4-6I 5).

Coube a Lavoisier decifrar o quebra-cabeças armado por seus antecesssores. Ele o fez deferindo um golpe mortal na teoria do flogisto.

Antoine Laurent Lavoisier (I743-I794), o fundador da química moderna, era descendente de família rica. Nasceu em Paris e teve educação esmerada. Primeiramente estudou direito, porém desde cedo sentiu-se atraído pela investigação científica e montou seu próprio laboratório. Aos 25 anos já era membro da Academia de Ciências da França, quando se casou com Marie-Anne Paulze, de treze anos de idade, filha do diretor da Companhia das Índias.

Inicialmente verificou que o óxido de ferro, quando aquecido, se transformava em ferro, perdendo peso e liberando gás com as mesmas propriedades do "ar do fogo". Chamou a esse gás oxigênio (que produz ácido). Concluiu que o fenômeno da combustão deveria ser interpretado ao contrário do que 
ensinava a teoria flogística: em lugar de perder flogisto, elemento imaginário que não deveria existir, os corpos quando se queimam, ou se oxidam, ou absorvem oxigênio.

Teve a intuição de que o calor animal resultava de uma combustão interna, lenta, na qual seria consumido o oxigênio do ar inspirado, e desprendido o "ar fixo", que identificou ao gás carbônico. Atribuiu a cor vermelha do sangue arterial ao oxigênio e a cor escura do sangue venoso ao gás carbônico. Comparou a produção do calor animal à queima do carvão, em que há consumo de oxigênio e produção de gás carbônico e água.

Lavoisier acreditava, e este foi o seu único erro, que a combustão se desse nos pulmões, onde o sangue entraria em contato com o ar inspirado, e que o calor gerado nos pulmões seria distribuído pelo sangue a todo o corpo. Esta hipótese foi refutada por Lagrange. Lavoisier, considerado um dos maiores gênios de todos os tempos, foi condenado pela Revolução Francesa de 1793 a morrer na guilhotina, aos 5 I anos de idade, por suas ligações com a realeza, tendo sido decapitado em 8 de maio de 1794 (Porter, 1994, p. 4I4; Fahraeus, op. cit., pp. 589-592)

Joseph Louis Lagrange (I736-I8I3), matemático e astrônomo francês, com base em cálculos, demonstrou que se a combustão ocorresse somente nos pulmões, a produção local de calor seria tão intensa que lesaria o parênquima pulmonar. Defendeu a ideia de que o consumo de oxigênio e a produção de gás carbônico se dariam em todos os órgãos, realizando-se nos pulmões apenas a troca de gases, o que foi confirmado posteriormente (Fahraeus, op. cit., p. 592).

Pierre Simon Laplace (I749-I 827), matemático francês e amigo de Lavoisier, submeteu esta hipótese a uma análise matemática, comparando a quantidade de gás carbônico eliminado com o calor produzido por um animal em dado período de tempo. A seguir mediu o calor e o gás carbônico produzido pela combustão de uma certa quantidade de carvão. Concluiu Laplace que o calor produzido, assim como o gás carbônico produzido, tanto num como noutro caso, é proporcional ao consumo de oxigênio. (Idem, ibidem)

Heinrich Gustav Magnus (I 802-I870), químico e fisiologista alemão, dosou pela primeira vez o oxigênio e o gás carbônico no sangue arterial e venoso, comprovando, assim que a utilização de oxigênio e a eliminação de gás carbônico se passam na intimidade dos tecidos (Morton, I983, p. I2I). 
A decifração do enigma da respiração resultou das investigações realizadas por quatro físicos, um farmacêutico, três químicos e dois matemáticos, cabendo o maior mérito, sem sombra de dúvida, a Lavoisier.

Ironicamente, o único médico que participou dessa empreitada, que foi Stahl, o fez em sentido negativo, lançando a teoria do flogisto, elemento imaginário criado pela fantasia, sem nenhuma base científica, e que dificultou a compreensão do liame existente entre a respiração e a produção do calor animal.

Houve grande resistência do mundo científico em abandonar a teoria flogística e aceitar as novas ideias de Lavoisier, que representaram uma revolução só comparável à descoberta da circulação por Harvey.

\section{Referências Bibliográficas}

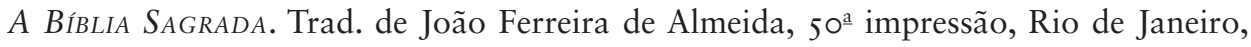
Imprensa Bíblica Brasileira, I98 I.

Entralgo, P. L. La Medicina Hipocrática. Madrid, Revista do Ocidente, I970.

Fahraeus, R. História da Medicina. Barcelona, Ed. Gustavo Gili, I956.

LECA, A.-P. La médecine égyptienne au temps de pharaons. Paris, Ed. Roger Dacosta, I97I. Lopes, O. C. A Medicina no Tempo. São Paulo, Edusp/Melhoramentos, I969.

Major, R. H. A History of Medicine. Oxford, Blackwell Scientific Publications, I954. Morton, L. A Medical Bibliography (Garrison and Morton). London, Gower, I983.

Porter, R. The Biographical Dictionary of Scientists. New York, Oxford University Press, I994. 